\title{
Design of Acoustic Signals for a Seal Deterrent Device
}

\author{
Arturs Aboltins" (Senior Researcher, Institute of Radioelectronics, Riga Technical University, Riga, Latvia), \\ Juris Grizans (Researcher, Institute of Radioelectronics, Riga Technical University, Riga, Latvia), \\ Dmitrijs Pikulins (Senior Researcher, Institute of Radioelectronics, Riga Technical University, Riga, Latvia), \\ Maris Terauds (Senior Researcher, Institute of Radioelectronics, Riga Technical University, Riga, Latvia), \\ Maris Zeltins (Researcher, Institute of Radioelectronics, Riga Technical University, Riga, Latvia)
}

\begin{abstract}
During the past decade, attacks by grey seals on fishing nets in the Baltic Sea have caused considerable loss of fish catch and damage to fishing gears. One of the approaches to reduce the number of seal attacks on fishing nets is to use acoustic deterrent devices (ADDs). Unfortunately, most of the commercially available ADDs are not well suited to the deployment in the sea and require considerable additional investments. The objective of the present research is to develop a compact and cost-efficient ADD for deployment in the sea environment. This paper is devoted to the design of acoustic signals for a prototype ADD. Signals from other experimental and commercially available ADDs are studied and compared. Moreover, limitations imposed by the underwater environment, transducers, battery power, and fish hearing are analysed and considered during the development of signal patterns. The results of tests conducted in an artificial reservoir and in the sea are presented.
\end{abstract}

Keywords - Acoustic applications; Acoustic measurements; Acoustic wave; Seals; Signal synthesis; Underwater acoustics; Underwater communication.

\section{INTRODUCTION}

An urgent problem facing the Baltic coastal fisheries in the past decade is the rapidly growing number of grey seals in the Baltic Sea. Animals, in search of food, are gaining new territories and damaging fishing nets and gears leading to almost complete loss of catch. On the other hand, the grey seal and other seal species are indigenous and specially protected species in the Baltic region whose protection is simultaneously required by the so-called Habitats Directive and the Convention on the Protection of the Marine Environment of the Baltic Sea Area (HELCOM).

One of the most effective solutions to the reduction of the losses caused by seals is to use an underwater acoustic deterrent device (ADD), which allows keeping seals away from fishing nets. Research [1] describes the impact of ADDs on the reduction of damage to fishing in the Baltic Sea due to seal activity. The authors of this paper have made several conclusions about the efficiency and side effects of commercially available seal scarers. Most notably, it was concluded that using ADDs leads to a noticeable reduction in damage caused by seals. However, the authors noted the need for hardware improvements to make an ADD more secure and easier to use.

Many of the existing devices were developed 10-15 years ago, at a time when the question of repelling seals was not yet active in the focus of researchers' attention. Since then, a number of important studies have been carried out that assess the effects of various signals on seals and other marine species. However, ADDs that are not modified for years (but are still for sale) do not allow the user to modify signal parameters according to new discoveries and scientific evidence and continue to send ineffective signals to deter seals from fishing nets, thus affecting the lives of other marine inhabitants.

Whereas most of the commercially available devices are well suited for fish farms, using them in the sea requires substantial investments in mechanical components and waterproof power supplies. Moreover, in an ideal case, acoustic signals used for deterring seals must be adjustable for the battery level, sound propagation conditions, transducer, and fish species.

Keeping these limitations and requirements in mind, our group of researchers has developed an advanced ADD for use in the sea. This paper is devoted to the design of acoustic signals used in a seal scarer device.

\section{REVIEW OF EXISTING ADDS}

At first, we will provide a short introduction to the used terminology regarding acoustic signals.

Sound pressure level (SPL) $L_{\mathrm{p}}$ is a logarithmic measure of the effective sound pressure $P$ relative to a reference value $P_{0}=1 \mu P_{\mathrm{a}}$ :

$$
L_{\mathrm{P}}=20 \log _{10} \frac{P}{P_{0}} .
$$

The sound exposure level (SEL) describes the impact on a living creature caused by a sound with a given SPL $L_{\mathrm{p}}$ and duration $\tau$ :

$$
L_{\mathrm{E}}=L_{\mathrm{P}}+10 \log _{10}(\tau)
$$

\footnotetext{
${ }^{*}$ Corresponding author

E-mail: arturs.aboltins_1@rtu.lv
} 
TABLE I

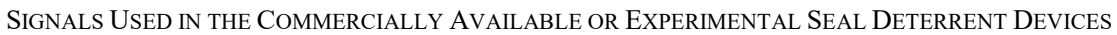

\begin{tabular}{|c|c|c|c|c|c|c|c|c|}
\hline Device & Waveform & $\begin{array}{l}\text { Source level } \\
{[\mathrm{dB}]}\end{array}$ & $F[\mathbf{k H z}]$ & $\tau[\mathrm{ms}]$ & $T[\mathrm{~ms}]$ & $B$ [ms] & $L[\mathbf{s}]$ & $\begin{array}{l}L \text { duty } \\
\text { cycle }\end{array}$ \\
\hline Mate \& Harvey [3] & Frequency-modulated pulses & unknown & $8-20$ & $1-32$ & 0 & $1-32$ & $0-1$ & random \\
\hline $\begin{array}{l}\text { Ferranti-Thomson } \\
\text { MK2 Seal Scrammer }\end{array}$ & $\begin{array}{l}\text { Pulses of } 5 \text { different frequencies, which are } \\
\text { ordered in } 5 \text { different combinations }\end{array}$ & unknown & $4-40$ & 20 & 40 & 20000 & $\begin{array}{l}600- \\
3600\end{array}$ & $3 \%$ \\
\hline $\begin{array}{l}\text { Ace-Aquatec Silent } \\
\text { Scrammer }\end{array}$ & $\begin{array}{l}\text { Pulses of } 28 \text { different frequencies, which are } \\
\text { ordered in } 64 \text { different combinations }\end{array}$ & 193 & $4-40$ & $3.3-14$ & $\begin{array}{l}33.2- \\
48.5\end{array}$ & 5000 & $\begin{array}{l}50- \\
600\end{array}$ & $50 \%$ \\
\hline Airmar dB Plus & sinusoid & 192,198 & 10.3 & 1.4 & 40 & 2250 & 4500 & $50 \%$ \\
\hline Terecos DSMS-4 & Single tone, chirps & 172 & $\begin{array}{l}1.8-3.0 \\
2.4-6.0\end{array}$ & 8 & $8-16$ & $\begin{array}{l}200- \\
8000\end{array}$ & 180 & $11 \%$ \\
\hline $\begin{array}{l}\text { Lofitech universal or } \\
\text { seal scarer }\end{array}$ & Sinusoid & 182 & $\begin{array}{l}14.9 \text { or } \\
15\end{array}$ & 550 & 1000 & 5500 & $20-60$ & $\begin{array}{l}10- \\
25 \%\end{array}$ \\
\hline Akamatsu et al. [4] & Sinusoid, sweep & 165 & $8,1-4$ & 5000 & 0 & 5000 & 10 & $20 \%$ \\
\hline
\end{tabular}

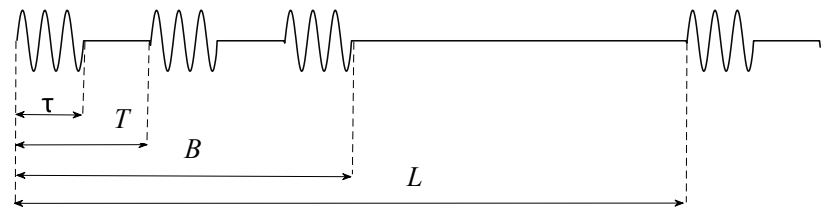

Fig. 1. Illustration of waveform parameters.

As we see, exposing the organism for $10 \mathrm{~s}$ to sound gives the same result as exposing it to a $10 \mathrm{~dB}$ stronger sound for $1 \mathrm{~s}$.

Research [2] provides a review of applications of ADDs, their efficiency and environmental impact. Authors review several commercially available devices from FerrantiThompson, Ace-Aquatec, Airmar, Terecos Ltd, Lofitech and scenarios of using them.

Some of the reviewed devices are considered acoustic harassment devices (AHDs) as they can cause actual pain and can lead to temporary or permanent damage to animal hearing. Table I provides an overview of the signals used in the commercially available or experimental ADDs and AHDs. An illustration of the parameters used in Table I is shown in Fig. 1. As we see from the table, there is a big difference between signals used for deterring seals from the fishing nets.

Part of the devices (Lofitech, Akamatsu) use simple singletone signals, whereas other devices provide a wide range of various sounds. The ability to generate certain sounds can be restricted by several factors, such as transducer design, ease of use, power budget.

The results of the experiments in the Baltic Sea presented in [1] and [5] show that animals can habituate to simple and periodic sounds; therefore, a large degree of randomization of the frequency, timing and the waveform is necessary. However, in the case of seasonal fishing activities, the problem is less urgent, and habituation is observed only at the end of each season.

The experiments in the sea [1] have outlined the drawbacks of commercial ADDs employed in these experiments. For example, the authors report the necessity to reduce the duty cycle to $4.5 \%$ ( $250 \mathrm{~ms}$ pulse, $55 \mathrm{~s}$ pause) to prolong the duration of device operation in the sea without recharging.

\section{SIGNAL DESIGN}

\section{A. Source Level}

The loudness of underwater sounds must be carefully considered as it directly influences the activity of animals and can lead to hearing impairments. For example, in paper [6], it is concluded that the deterrent effect of sound depends on the presence of food. If there is no food, seals leave the ADD area at a source level of $135 \mathrm{~dB}$, whereas if the seal sees food, the threshold increases to $145 \mathrm{~dB}$.

TABLE II

IMPACT OF SEL ON HEARING IMPAIRMENTS

\begin{tabular}{|l|l|l|}
\hline SEL $[\mathbf{d B}]$ & TTS radius $[\mathbf{m}]$ & PTS radius $[\mathbf{m}]$ \\
\hline 221 & 100 & 60 \\
\hline 203 & 10 & 7 \\
\hline 183 & 1 & 0.5 \\
\hline 163 & 0 & 0 \\
\hline
\end{tabular}

Too loud sounds can lead to a temporary threshold shift (TTS) or a permanent threshold shift (PTS) in hearing. This, in turn, will decrease the efficiency of ADD, as deaf animals do not feel discomfort caused by such devices. Table II presents the relationship between SEL and hearing impairments at various distances.

Finally, too weak sounds will serve as a "dinner bell" and, instead of deterring seals, will attract them to the fishnets, as animals can quickly learn the connection between the noise and the presence of food.

\section{B. Frequency Spectrum}

Hearing studies devoted to seals and other related species have shown that their best sensitivity to sounds lies within the 20-30 kHz range. On the other hand, it is well known [7] that the absorption coefficient of sound in seawater grows proportionally to the frequency; therefore, the use of lower frequency signals is more energy-efficient.

The results of research [8] show that specific broad-spectrum signals may affect the communication, predation and mating habits of animals. Therefore, the waveform of the ADD signal has to be designed with high precision and awareness of the impact on sea inhabitants. At the same time, ADDs should not deter fishes from the nets as it would render the fishery useless. To avoid this problem, the authors carried out a series of 
experiments on a fish farm. The results of the experiments show that the tested fish species (trout and salmon) react to sounds with frequencies up to $300 \mathrm{~Hz}$ and that sounds above $4 \mathrm{kHz}$ do not affect their behaviour.

Another factor that affects the selection of the waveforms is the characteristics of the underwater projector (speaker). Typically, transducers that cover a wide range of frequencies, for example, underwater speakers for swimming pools, have high cost and limited capabilities to provide high sound pressure levels. Devices produced especially for deterring purposes are more cost-efficient and louder; however, they have an uneven frequency response and require adaptation of the transmitted signals to a particular speaker.

\section{Window}

In research [6], it is shown that to cause the startle reflex in grey seals, the sound pressure must rise from zero to full intensity in less than $20 \mathrm{~ms}$. Moreover, it is shown that a sharper rising edge causes a stronger deterrent effect on animals. However, waveforms with sharp edges have many highfrequency harmonics in the spectrum, which lead to a waste of energy and may cause undesired side effects such as intermodulation products at low frequencies that deter fishes. In our device, we use bursts of short pulses with different frequency variation rules. Pulse shaping is applied to separate pulses with duration $\tau$ (see Fig. 1) within the burst. We employed the well-known Hann (raised cosine) window:

$$
u(t)=0.5\left[1-\cos \left(\frac{\pi t}{a}\right)\right],
$$

where $a$ is the duration of the pulse edge and it must be less or equal to half of the pulse duration $\tau$ within the burst (see Fig. 1). The parameter $a$ can be adjusted in order to maintain the necessary sharpness of the edges along with low sound intensity at higher frequencies.

\section{Pulse Timing}

As it is shown in Section II, the sound exposure level (SEL) depends on the duration of the signal. Therefore, longer pulses or bursts have a larger impact. However, long pulses shorten battery life and facilitate habituation to the deterrent signal. Another parameter that must be considered is the pause between the pulses or bursts. Larger pauses between the pulses save battery life. However, too long pauses will weaken the deterrent effect, as predators can get into the fishing nets during the silence period. Moreover, a large pause increases the probability of PTS or deafness due to a very small distance between the speaker and an unaware animal. To calculate the maximum silence interval $t_{\mathrm{s}}$, we have to know the maximum swimming speed $v_{\mathrm{m}}$ of a seal and the maximum distance $R$ at which seals notice the signal. Following [9], the swimming speed of a grey seal is typically in the range of $0-1.5 \mathrm{~m} / \mathrm{s}$. According to [10]-[12], the avoidance threshold SPL for grey seals is approximately $140 \mathrm{~dB}$. Considering the sound propagation model from [13] as well as real measurements from [12], [14], the sound absorption in seawater can be described using the following approximate formula:

$$
K=20 \log _{10} R,
$$

where $K$ is the attenuation in $\mathrm{dB}$ and $R$ is the distance from the source. Assuming that the SPL of the source is $180 \mathrm{~dB}$, the distance at which we get $K=40 \mathrm{~dB}$ lower level, i.e., $140 \mathrm{~dB}$ is:

$$
R=10^{\frac{(180-140)}{20}}=100[\mathrm{~m}] .
$$

This result means that the effective deterrence radius of ADD is equal to $100 \mathrm{~m}$. Neglecting the speed of sound in the water (approximately $1480 \mathrm{~m} / \mathrm{s}$ ), we can calculate that the silence interval must not exceed:

$$
t_{\mathrm{s}}=\frac{R}{v_{\mathrm{m}}}=\frac{100}{1.5}=67[\mathrm{~s}]
$$

In accordance with Table $\mathrm{I}$, there is a large variety of repetition intervals (parameter $L$ in Fig. 1) and duty cycles (duty cycle of $L$ ) used in various commercial ADDs. Some of the devices are not suitable for deterring seals due to too long silence periods.

\section{E. Software-Based Generator}

For the selection of the signal parameters and laboratory testing, a MATLAB App Designer ${ }^{\circledR}$ application was created (see Fig. 2).

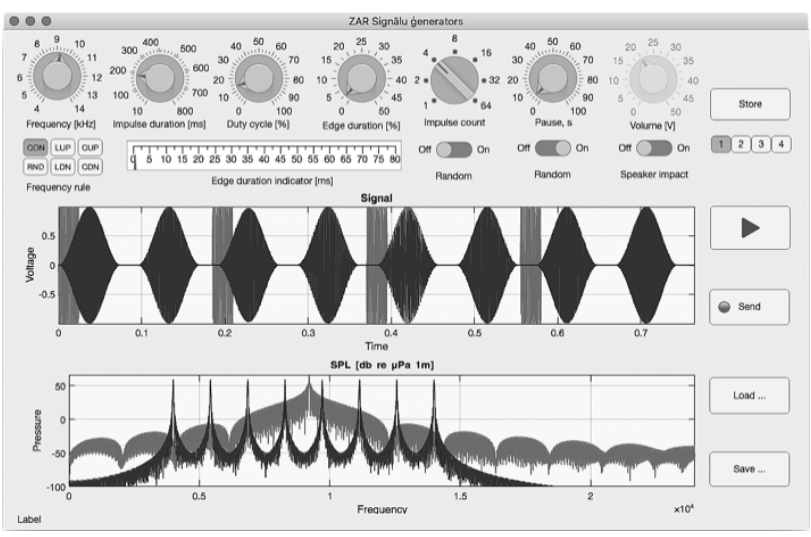

Fig. 2. Application for the signal parameter adjustment and testing.

The knobs at the top of the window allow adjusting signal parameters, whereas the buttons on the left side allow selecting the rule of frequency change (see explanation in Table III).

TABLE III

RULES OF FREQUENCY CHANGE

\begin{tabular}{|l|l|}
\hline Acronym & Frequency change rule \\
\hline CON & Constant $f_{\max }$ \\
\hline LUP & Linearly increasing frequency from $4 \mathrm{kHz}$ to $f_{\max }$ \\
\hline CUP & $\begin{array}{l}\text { Linearly increasing frequency from } 4 \mathrm{kHz} \text { to } f_{\max } \text {, circularly } \\
\text { shifted by a random offset }\end{array}$ \\
\hline RND & Random in a range from $4 \mathrm{kHz}$ to $f_{\max }$ \\
\hline LDN & Linearly decreasing frequency from $f_{\max }$ to $4 \mathrm{kHz}$ \\
\hline CDN & $\begin{array}{l}\text { Linearly decreasing frequency from } f_{\max } \text { to } 4 \mathrm{kHz} \text {, circularly } \\
\text { shifted by a random offset }\end{array}$ \\
\hline
\end{tabular}

By pressing the "Store" button, it is possible to save the state of the knobs (i.e., signal parameters) into one of four memory cells. The content of the memory cells can be loaded from the file or saved to the file. By pressing the "Send" button, four sets 
of parameters can be transmitted via serial port to the prototype device.

The application allows for the playback of acoustic signals via computer speakers. This feature allows using the application for laboratory testing and for the audio amplifier and underwater transducer measurements. Moreover, this application has been used to explore the impact of ADD signals on fishes in a fish farm.

The waveform and spectrum plots at the middle of the window allow monitoring and comparing their characteristics, such as duty cycle and spectral leakage. It is possible to monitor signal characteristics considering the frequency response of a particular speaker that can be loaded from the file.

\section{F. Hardware-Based Generator}

To implement a waveform generator in the prototype of an acoustic deterrent device, we use a popular microcontroller unit (MCU) ATmega328P in conjunction with a function generator integrated circuit (IC) XR-2206 from EXAR Corporation. Using pulse-width modulation (PWM) outputs, the program of the microcontroller performs real-time control of amplitude and frequency of acoustic signals generated by the function generator IC. Loading of signal parameters into the MCU is performed utilizing serial communication between the computer running the MATLAB application (see Section IV-A) and the MCU program.

One of the important features of the developed software is the ability to go into "sleep" mode between the bursts of acoustic signals. It enables the extremely power-efficient operation of the acoustic signal generator.
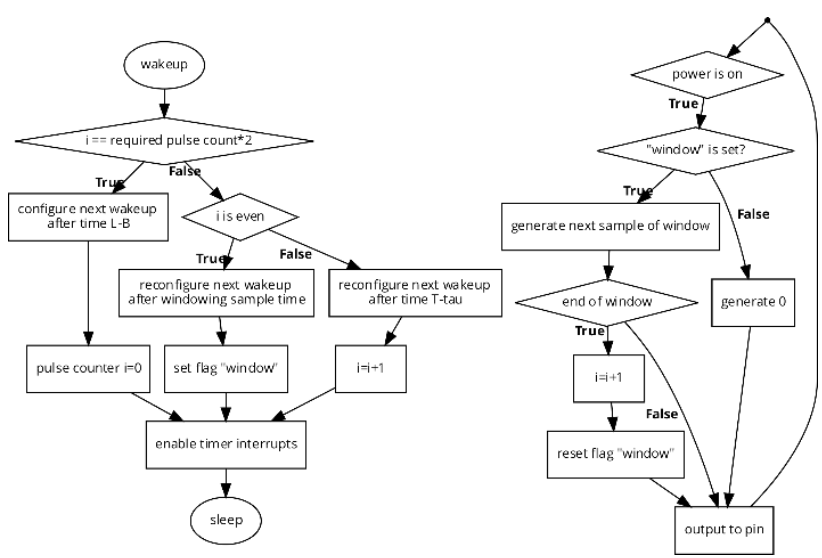

Fig. 3. Flowchart of windowing function in MCU.

Figure 3 depicts the flowchart of the part of the MCU program that controls the generation of the envelope of an acoustic signal along with sleep function. Apart from the mentioned tasks, the microcontroller program controls the frequency of the acoustic signal and is responsible for communication with other parts of the prototype, such as remote control and telemetry.

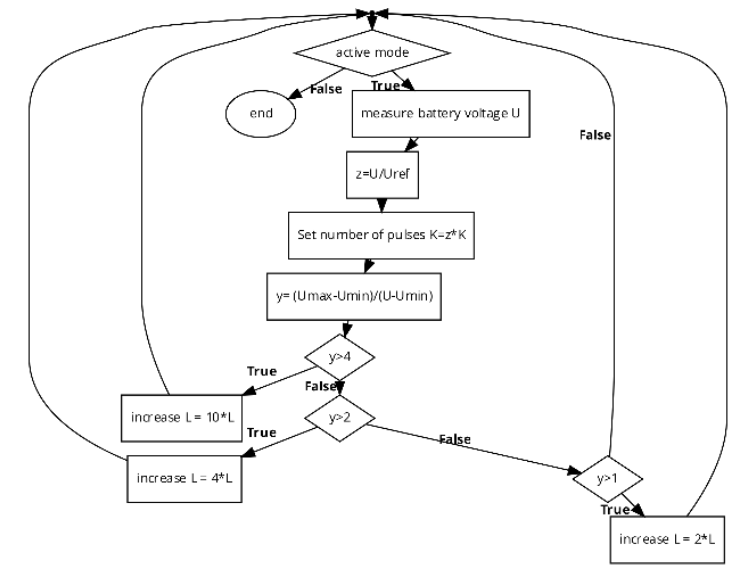

Fig. 4. Algorithm for adjusting signal parameters according to the battery level.

To maintain the maximum power efficiency of the ADD, the hardware-based generator is equipped with a function, which allows adjusting parameters of the acoustic signals depending on the battery level.

Thus, it is possible to prolong intervals between recharging of the battery, when the device is lifted out of the water and fishing gears remain unprotected. A simplified algorithm that is used in the function is shown in Fig. 4.

\section{TESTING}

The developed prototype of ADD has undergone several testing cycles, including laboratory testing, testing in the river, and sea tests. In this paper, we will pay attention to the testing of signal generation and underwater propagation.

\section{A. Testing in the Reservoir}

To estimate speaker characteristics and examine signal propagation in water, we performed a series of tests in a boat bay at the bank of the Daugava River. The experimental setup is depicted in Fig. 5. For the signal acquisition, a high-accuracy hydrophone Reson TC4032-1 was used.

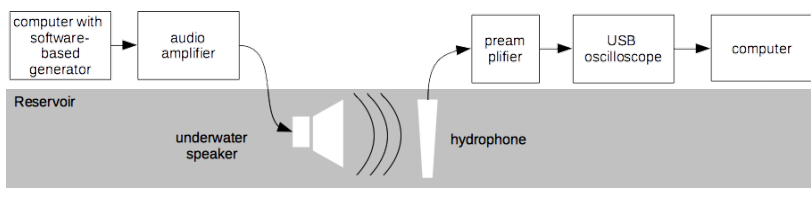

Fig. 5. Setup for testing of acoustic signal transmission in the reservoir.

The purpose of the tests was to estimate:

1) Dependence of SPL on the distance from the speaker;

2) Impact of water flow on the propagation of the sound;

3) Impact of the underwater medium on the waveform and spectral characteristics of the signal.

We observed large variations of signal level during the measurement sessions. 


\section{H1+1+1+1+1+1+1+1+1}

Fig. 6. Example of a waveform captured by the oscilloscope during reservoir testing.

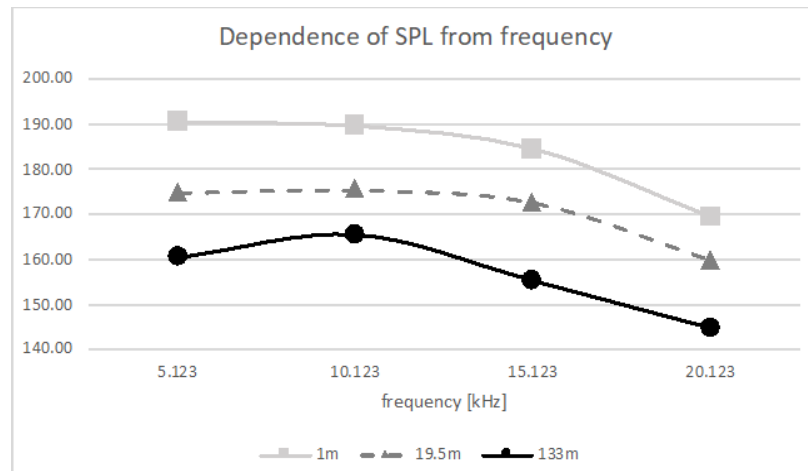

Fig. 7. Dependence of the average sound pressure level on the frequency at various distances between the speaker and the hydrophone.

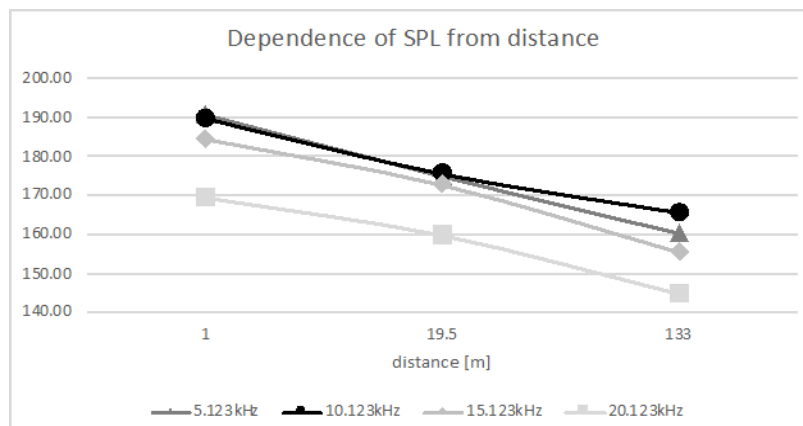

Fig. 8. Dependence of the average sound pressure level on the distance between the speaker and the hydrophone.

Variable-frequency pulses transmitted with a $0.5 \mathrm{~s}$ interval showed considerable amplitude variations (see Fig. 6) due to water streams and frequency-dependent absorption of the acoustic waves in the water.

Figures 7 and 8 show frequency-dependent attenuation at different distances between the speaker and the hydrophone. It can be seen that attenuation at higher frequencies is stronger as expected in theory [7].

Moreover, the SPL is inversely proportional to the distance between the speaker and the hydrophone. The obtained measurement results fit well with the theory presented in previous sections.

As we see in Fig. 8, at a distance of $133 \mathrm{~m}$, the SPL decreases by approximately $30 \mathrm{~dB}$, whereas, according to (4), the signal attenuation should be about $42 \mathrm{~dB}$. The difference could be caused by shallow water and underwater reflection of acoustic waves from the concrete decking of the pier.

\section{B. Testing in the Sea}

The prototype of ADD was tested in sea conditions. Table IV presents the parameters of four different signals employed during the sea tests. The results of the tests show that the prototype of ADD emitting the mentioned signals is capable of deterring seals from fishing nets. Compared to the time periods when no deterrent device was used, the catch was several times higher and fishing nets were not damaged. During a four-day continuous test period, habituation of seals to the deterrent signals was not observed. Habituation over longer periods will be explored in future research.

TABLE IV

SignALS USED FOR TESTING IN THE SEA

\begin{tabular}{|l|c|c|c|c|c|c|}
\hline f mode & $\begin{array}{c}\boldsymbol{f}_{\max } \\
{[\mathbf{k H z}]}\end{array}$ & $\begin{array}{c}\boldsymbol{T} \\
{[\mathbf{m s}]}\end{array}$ & $\begin{array}{c}\tau \\
{[\mathbf{m s}]}\end{array}$ & $\begin{array}{c}\boldsymbol{a} \\
{[\mathbf{m s}]}\end{array}$ & $\begin{array}{c}\boldsymbol{B}_{\max } \\
{[\mathbf{m s}]}\end{array}$ & $\begin{array}{c}\boldsymbol{L}_{\max } \\
{[\mathbf{s}]}\end{array}$ \\
\hline RND & 15 & 16 & 16 & 8 & 640 & 60 \\
\hline CUP & 15 & 16 & 16 & 5 & 640 & 60 \\
\hline CON & 13 & 10 & 10 & 0 & 640 & 60 \\
\hline CON & 10 & 100 & 50 & 25 & 400 & 10 \\
\hline
\end{tabular}

\section{CONCLUSION}

This paper has presented the design and testing of signals for an acoustic deterrent device (ADD), which is aimed at deterring seals from fishing nets in the sea and, therefore, reducing predation on salmon and other valuable fish species. Potential users of these devices are medium and large fishing companies that cast their fishing nets in coastal regions of the Baltic Sea.

The design methodology is based on the research of scientific literature about deterrent devices and on the study of existing commercial ADDs. Moreover, the authors have performed a series of tests to ensure no deterrent effect on fishes. Particular attention has been paid to simplicity and efficiency of operation along with minimal maintenance.

Reservoir testing confirmed theoretical considerations about sound propagation models, frequency-dependent sound absorption in water and its impact on signal parameters at different distances from the underwater speaker. Moreover, testing in the reservoir allowed testing such system components as an audio amplifier and power supply circuitry.

Testing in the sea confirmed the effectiveness of deterrent signals and the suitability of the developed hardware prototype for commercial deployments. However, sea tests revealed that fishing nets became damaged within less than one day after the ADD was removed. Therefore, one of the largest challenges that has to be resolved now is to find a way to ensure continuous operation of the deterrent device along with the necessity to recharge or change the batteries.

\section{REFERENCES}

[1] A. Fjälling, M. Wahlberg, and H. Westerberg, "Acoustic harassment devices reduce seal interaction in the Baltic salmon-trap, net fishery," ICES J. Mar. Sci., vol. 63, no. 9, pp. 1751-1758, 2006. https://doi.org/10.1016/j.icesjms.2006.06.015

[2] T. Götz and V. M. Janik, "Acoustic deterrent devices to prevent pinniped depredation: Efficiency, conservation concerns and possible solutions," Mar. Ecol. Prog. Ser., vol. 492, pp. 285-302, 2013. https://doi.org/10.3354/meps10482

[3] B. R. Mate, R. F. Brown, C. F. Greenlaw, J. T. Harvey, and J. Temte, "An Acoustic Harassment Technique to Reduce Seal Predation on Salmon," in Acoustical Deterrents in Marine Mammal Conflicts with Fisheries, 1986, pp. 23-36.

[4] T. Akamatsu, K. Nakamura, H. Nitto, and M. Watabe, "Effects of Underwater Sounds on Escape Behavior of Steller Sea Lions," Fish. Sci., vol. 62 , no. 4, pp. 503-510, 1996. https://doi.org/10.2331/fishsci.62.503

[5] M. J. Brandt, C. Höschle, A. Diederichs, K. Betke, R. Matuschek, S. Witte, and G. Nehls, "Effectiveness of a sealscarer in deterring harbour porpoises (Phocoena phocoena) and its application as a mitigation measure during offshore pile driving," A Rep. Comm. by Ger. Fed. Minist. Environ. Nat. Conserv. Nucl. Saf., no. March, p. 110 pp., 2012. 
[6] T. Götz and V. M. Janik, "Repeated elicitation of the acoustic startle reflex leads to sensitisation in subsequent avoidance behaviour and induces fear conditioning.," BMC Neurosci., vol. 12, no. 1, p. 30, 2011. https://doi.org/10.1186/1471-2202-12-30

[7] A. Stefanov and M. Stojanovic, "Design and Performance Analysis of Underwater Acoustic Networks," Sel. Areas Commun. IEEE J., vol. 29 , no. 10, pp. 2012-2021, 2011. https://doi.org/10.1109/JSAC.2011.111211

[8] G. D. Hastie, C. Donovan, T. Götz, and V. M. Janik, "Behaviora responses by grey seals (Halichoerus grypus) to high frequency sonar," Mar. Pollut. Bull., vol. 79, no. 1-2, pp. 205-210, 2014 https://doi.org/10.1016/j.marpolbul.2013.12.013

[9] J. Gordon, D. Thompson, D. Gillespie, M. Lonergan, S. Calderan, B. Jaffey, and V. Todd, "Assessment of the potential for acoustic deterrents to mitigate the impact on marine mammals of underwater noise arising from the construction of offshore windfarms," Cowrie Ltd, July 2007.

[10] T. Götz and V. M. Janik, “United States Patent," US 8,289,812 B2, 2012

[11] R. A. Kastelein, L. Helder-Hoek, R. Gransier, J. M. Terhune, N. Jennings, and C. A. F. de Jong, "Hearing thresholds of harbor seals (Phoca vitulina) for playbacks of seal scarer signals, and effects of the signals on behavior," Hydrobiologia, vol. 756, pp. 75-88, 2015 https://doi.org/10.1007/s10750-014-2152-6

[12] J. R. Nedwell, a G. Brooker, S. a H. Bryant, and R. J. Barham, "Measurements of Underwater Noise Generated by Acoustic Mitigation Devices," ResearchGate, December, 2011.

[13] S. Jie, Z. Weisong, J. Xiangjun, Z. Xin, and R. Malekian, "Underwater broadband acoustic scattering modelling based on FDTD," Elektron. ir Elektrotechnika, vol. 21, no. 2, pp. 58-64, 2015. https://doi.org/10.5755/j01.eee.21.2.11513

[14] A. Müller and C. Zerbs, Offshore wind farms. Measuring instruction for underwater sound monitoring. BSH, Hamburg, 2011.

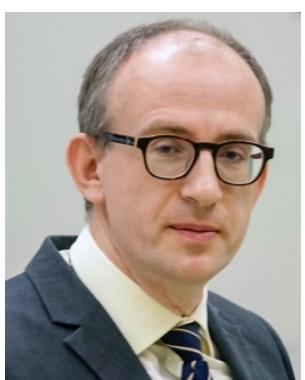

Arturs Aboltins received his Ph. D. in electronics and telecommunications from Riga Technical University in 2013. Before pursuing the doctoral degree, A. Aboltins held technical and management positions in the industry for more than ten years.

$\mathrm{He}$ is a senior researcher at the Institute of Radioelectronics and an Associate Professor and Head of the Department of Electronics Fundamentals of RTU. His research interests include underwater acoustics, the applications of unitary transforms and software-defined radio. He is the founder and organizer of scientific conferences "Advances in Wireless and Optical Communications (RTUWO)" and "Workshop on Microwave Theory and Techniques in Wireless Communications (MTTW)". He is the chair of the IEEE Latvia Section Communications, Microwave Theory and Techniques, Antenna and Propagation Joint Societies Chapter. The postal address: Azenes 12, Riga, Latvia, LV-1048.

E-mail: arturs.aboltins 1@,rtu.lv

ORCID iD: http://orcid.org/0000-0001-6901-9787

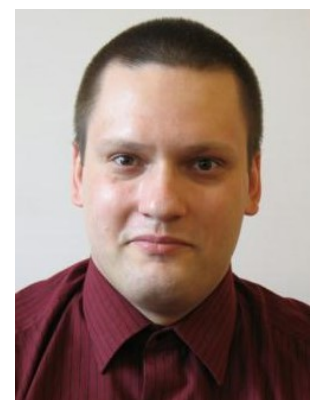

Juris Grizans holds a M. Sc. Ing. degree in electronics engineering form Riga Technical University (RTU), Latvia (2005). Currently he is a Doctoral student at the Institute of Radioelectronics, RTU.

$\mathrm{He}$ is a Researcher at the Institute of Radioelectronics and lecturer at Department of Electronics Equipment, RTU. His research interests are related digital electronics and microcontroller-based device development and programming.

E-mail: Juris.Grizans@,rtu.lv

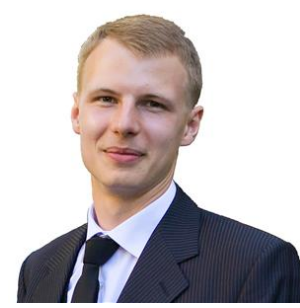

Dmitrijs Pikulins received his Doctoral (2012) degree in Electronics from Riga Technical University. $\mathrm{He}$ is an Associate Professor and a Senior Researcher at the Institute of Radioelectronics, Riga Technical University, Latvia. Moreover, Dmitrijs is an expert at the Latvian Academy of Sciences, a member of RTU Constitutional Assembly and the Head of the Institute of Radioelectronics. His research interests include wireless sensor networks, IoT, nonlinear chaotic systems, power electronics.

E-mail: dmitrijs.pikulins@,rtu.lv

ORCID iD: https://orcid.org/0000-0002-6768-6989

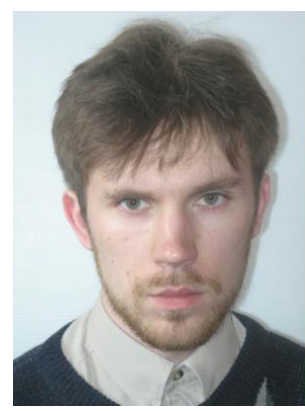

$\underline{0036}$

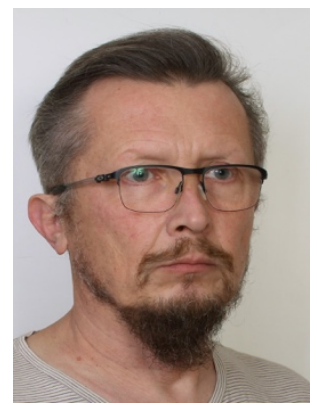

E-mail: maris.zeltins@rtu.lv
Maris Terauds holds a Dr. Sc. Ing. degree in electronics and telecommunications engineering from Riga Technical University (RTU), 2009. $\mathrm{He}$ is a Seniour Researcher at the Institute of Radioelectronics and assistant professor at the Department of Electronics Fundamentals, RTU, Latvia. His research interests are related to mixed signal ASIC design, wireless sensor network, IoT and FPGAs. Previous interest also related to application of unitary transform, using Doppler Radar for vehicle recognition.

E-mail: maris.terauds@rtu.lv

ORCID iD: https://orcid.org/0000-0001-6934-

Maris Zeltins holds a Dr. Sc. Ing.degree in electronics and telecommunications engineering from Riga Technical University (RTU), Latvia (1995). He is a Researcher at the Institute of Radioelectronics and assistant professor at the Department of Department of Radiosystems, RTU, Latvia. His research interests are related to analog design for audio and ultrasound applications, wireless power transfer etc. He is an member of TPC of the scientific conference "Workshop on Microwave Theory and Techniques in Wireless Communications (MTTW)". 